Chapter 5

\title{
Genetics of Sporadic Cerebral Amyloid Angiopathy
}

\author{
Kristiina Rannikmäe and Cathie Sudlow \\ Additional information is available at the end of the chapter \\ http://dx.doi.org/10.5772/58870
}

\section{Introduction}

Cerebral amyloid angiopathies (CAA) can be divided into sporadic and hereditary forms. This chapter is focused on the genetics of sporadic CAA, but will first consider hereditary forms in brief.

\subsection{Hereditary CAA}

Amyloid- $\beta$ protein $(A \beta)$, the commonest amyloid subunit implicated in sporadic forms of CAA, is also involved in certain hereditary forms. Several other proteins are also associated with rare familial diseases in which CAA is a characteristic morphological feature. [1] Missense mutations within or just outside the $\mathrm{A} \beta$ peptide coding region of the APP gene result in clinicopathological phenotypes of early onset Alzheimer's disease (AD) and are associated with a neuropathological phenotype which includes prominent CAA - for example hereditary cerebral haemorrhage with amyloidosis of Dutch type (HCHWA-D), or with Italian, Arctic, Iowa, Piedmont and Flemish mutations. Severe A $\beta$ CAA has also been well documented in cases of familial AD due to mutations in the presenilin (PSEN1 and PSEN2) genes. Familial CAAs associated with other proteins include BRI2 gene-related dementias (familial British dementia and familial Danish dementia), cystatin $C$ gene mutations in hereditary cerebral haemorrhage with amyloidosis of Icelandic type, TTR gene mutations in meningo-vascular amyloidosis, hereditary prion disease with premature stop codon mutations and mutated gelsolin gene in familial amyloidosis of Finnish type. [1]

\subsection{Sporadic CAA}

Sporadic cerebral amyloid angiopathy is characterised by deposition of $A \beta$ in leptomeningeal and cortical blood vessels. It has a prevalence in population-based autopsy studies of $20-40 \%$ 
in non-demented and 50-60\% in demented elderly people. [2] Neuropathological case-control and cross-sectional studies, as well as the increased incidence of intracerebral haemorrhage (ICH) in patients with Alzheimer's disease, suggest that CAA causes lobar ICH. [3, 4] CAA is also associated with increasing age, dementia, lobar brain microbleeds, leukoaraiosis, small cortical infarcts and superficial siderosis. [3, 5-7]

It is unknown why only a few people with CAA pathology develop an $\mathrm{ICH}$, but it seems likely to involve biological pathways additional to and distinct from those involved in vascular amyloid deposition. Cases of CAA with ICH not only have a greater proportion of amyloidladen blood vessels, [8] but also more often demonstrate severe CAA with associated vasculopathy. [8-11]

Identifying genetic polymorphisms associated with the presence of histopathologically confirmed CAA in general, as well as with the severe form of CAA thought to cause vessel rupture and $\mathrm{ICH}$, should increase our understanding of the mechanisms leading to CAA and associated diseases, including CAA associated ICH.

Polymorphisms in the apolipoprotein E gene (APOE) [12] are associated with ICH as well as with other conditions in which CAA may be involved, including subarachnoid haemorrhage, lobar brain microbleeds, and AD. [7, 13-18] In vitro studies have shown that APOE influences A $\beta$ conformation, fibril formation and toxicity, $[19,20]$ while in vivo mouse studies have confirmed a critical role for apolipoprotein $\mathrm{E}$ in $\mathrm{A} \beta$ deposition, toxicity and possibly clearance. $[21,22]$ It therefore seems likely that APOE influences risk of developing histopathologically confirmed, sporadic CAA. Other genetic polymorphisms are also likely to contribute to development of sporadic CAA.

Below we present and summarise the evidence for associations of polymorphisms in APOE or any other gene with histopathologically confirmed, sporadic CAA in adult humans. We then go on to consider the evidence for associations of APOE with the severe form of CAA. The evidence presented is based mainly on our two recently published systematic reviews of all relevant published studies, both of which incorporated a comprehensive search strategy, a thorough assessment of study quality, a series of meta-analyses, and an evaluation of the robustness of any positive findings to small study and other methodological biases. [23, 24] Figure 1 summarises the strategy used for identifying relevant studies and the numbers of studies (and study participants) identified.

\section{Genetic associations with histopathologically-confirmed, sporadic CAA}

While robust, large-scale evidence exists for an association of APOE with ICH attributed to CAA on the basis of clinical criteria, [15] studies assessing association of APOE with histopathologically confirmed CAA have had various methodological shortcomings (including small size), and reported results vary. Our systematic review of genetic associations with histopathologically confirmed, sporadic CAA sought all studies in which participants had been 


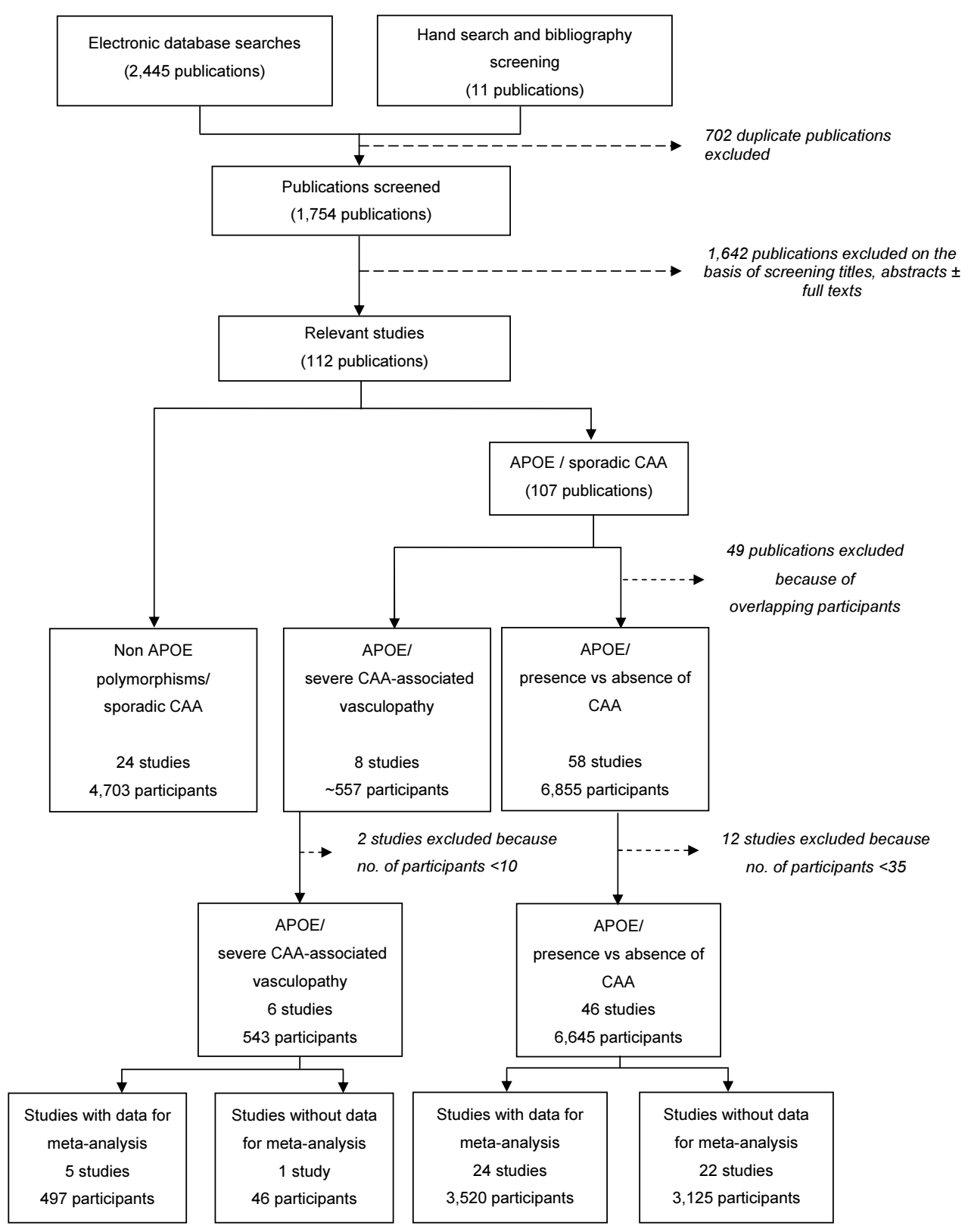

Figure 1. Selection of included studies 
genotyped for any genetic polymorphism and had CAA assessed pathologically (using autopsy or biopsy). [23] Studies that had assessed genetic associations with CAA-associated $\mathrm{ICH}(\mathrm{CAAH})$ versus CAA-free controls were excluded, because these would not be able to distinguish a genetic association with the presence of CAA histopathology from an association with ICH.

\subsection{APOE $\varepsilon 2 / \varepsilon 3 / \varepsilon 4$ polymorphism and sporadic CAA}

We identified 46 studies including 6645 participants with data about the APOE $\varepsilon 2 / \varepsilon 3 / \varepsilon 4$ polymorphism and sporadic CAA (Figure 1). [25-70] These studies had used autopsy brains from clinical autopsy collections, a brain bank or a population-based prospective study. Participants' mean age was 70 to 85 years in most studies and about half were male. Almost $90 \%$ of participants were of European ancestry while around $10 \%$ were from Asian populations (all Japanese). About $30 \%$ of participants had clinical dementia (mainly AD), about $10 \%$ were known not to be demented and dementia status was not specified for the remainder. There was substantial variation in overall study quality. Genotyping reporting quality [71, 72] was generally limited and methods for pathological assessment were very variable. Larger studies tended to be of higher quality. [23]

\subsubsection{APOE $\varepsilon 4$ and $C A A$}

Meta-analyses were possible of data from just over half of these studies (including just over half of the participants), and showed a significant association between $\varepsilon 4+$ genotypes and presence of CAA (OR 2.67, 95\% CI 2.31 to 3.08), although there was significant heterogeneity between the studies' results (Figure 2). There were no significant differences between subgroups of studies based on dementia status, ethnicity or overall study quality score (Figures 2 and 3). Six studies (443 participants) made only a qualitative statement, [27, 30, 33, 37, 40, 42] reporting either no significant association or a trend towards association with APOE $\varepsilon 4$, while 16 studies (2682 participants) provided no information about the association. [25, 28, 29, $31,32,34-36,38,39,41,43,46,47,50,57]$

Failsafe N calculations [73] showed that a null study of $>137,000$ participants would be required to bring the association of $\varepsilon 4+$ genotypes with CAA from the meta-analysis to a just statistically non-significant level. This makes it unlikely that there might plausibly be enough participants in unpublished, unreported or otherwise unretrieved null studies to make this significant result non-significant, and suggests that the association of APOE $\varepsilon 4+$ genotypes with histopathologcally confirmed, sporadic CAA is real and robust. Meta-analysis of the association of APOE $\varepsilon 4$ allele dose with CAA among 12 studies (1706 participants) providing quantitative data showed a significant increase in the odds of having CAA with increasing dose of the $\varepsilon 4$ allele (Figure 4$)$. Two further studies (117 participants) provided a qualitative statement about the association supported this result. [40, 64] Failsafe N calculations showed that it would require a null study of $>7000$ participants to bring the stronger association with CAA of $\varepsilon 4$ homozygous versus heterozygous genotypes to a just non-significant level, suggesting that the finding of a dose-response relationship between APOE $\varepsilon 4$ and CAA is real and robust. 


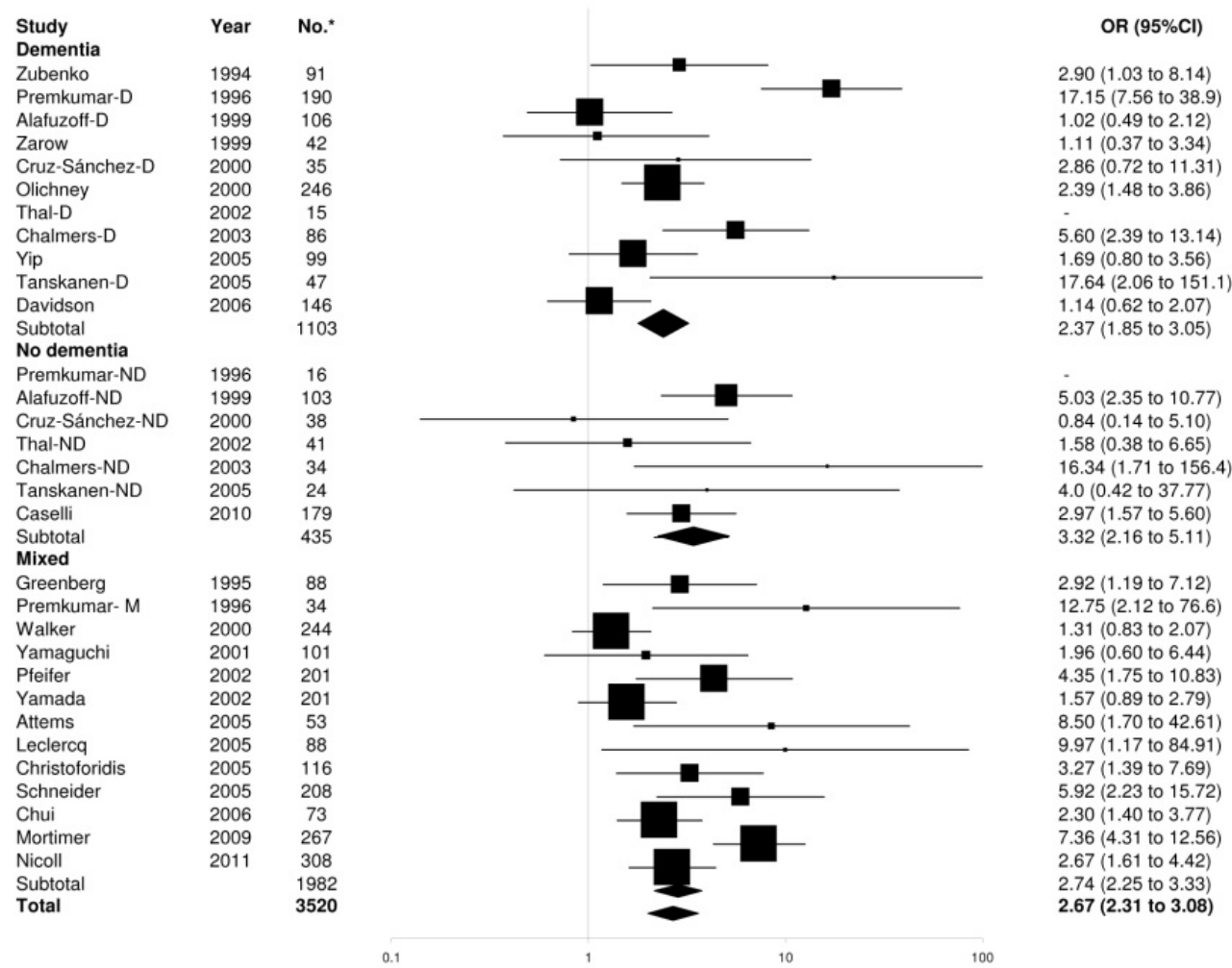

Presence of CAA decreased in participants with $\varepsilon 4$ allele $\quad$ Presence of CAA increased in participants with $\varepsilon 4$ allele

Generic inverse variance fixed-effects method; $p$ (overall effect) $<0.00001$

Tests for heterogeneity: $I^{2}=69 \% ; \chi_{28 d f}^{2}=89 . ; p<0.00001$

Tests for subgroup differences: $1^{2}=0 \% ; \chi_{2 d t}^{2}=1.9 ; p=0.38$

*Refers to number of participants included in analysis; 10 participants excluded because of missing data:

Christoforidis 2005 - 2 participants; Greenberg 1995 - 5 participants; Nicoll 2011 - 2 participants, Olichney 2000 - 1 participant.

$\mathrm{D}=$ clinically demented participants, $\mathrm{ND}=$ clinically not demented participants, $\mathrm{M}=$ demented and not demented participants

The squares represent study-specific odds ratios (ORs), with their size proportional to their statistical weight by the generic inverse variance method. Horizontal lines represent 95\% confidence intervals (Cls). Diamonds represent pooled ORs, and their width represents the $95 \% \mathrm{Cl}$. Higher score represents better study quality.

Reproduced from "Genetics of cerebral amyloid angiopathy: systematic review and meta-analysis" Rannikmäe K, Samarasekera N, Martīnez-Gonzālez NA, Al-Shahi Salman R, Sudlow C. Journal of Neurology Neurosurgery and Psychiatry 2013;84(901-8), with permission from BMJ Publishing Group Ltd.

Figure 2. Meta-analysis of association of APOE $\varepsilon 4+v s$ $\varepsilon 4$ - genotypes with CAA by participants' dementia status 


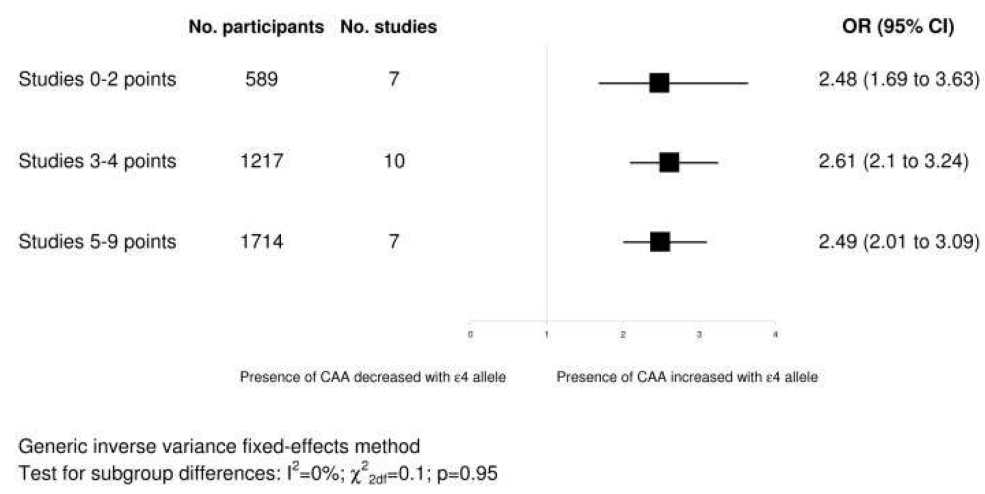

The squares represent pooled ORs and their width represents the $95 \% \mathrm{CI}$. Higher score represents better study quality. Reproduced from "Genetics of cerebral amyloid angiopathy: systematic review and meta-analysis" Rannikmäe K, Samarasekera N, Martīnez-Gonzālez NA, Al-Shahi Salman R, Sudlow C. Journal of Neurology Neurosurgery and Psychiatry 2013;84(901-8), with permission from BMJ Publishing Group Ltd.

Figure 3. Subgroup analysis based on study quality scores.

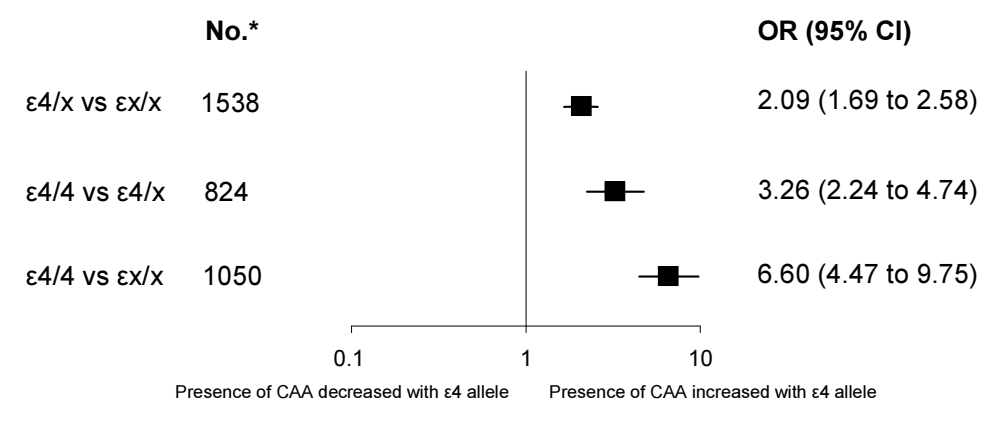

Generic inverse variance fixed effects method.

${ }^{*}$ Refers to number of participants included in the analysis.

The squares represent pooled ORs and their width represents the $95 \% \mathrm{Cl}$.

Figure 4. Meta-analysis of effects of APOE $\varepsilon 4$ dose ( $\varepsilon 4--/ \varepsilon 4+-/ \varepsilon 4++$ genotypes) on presence vs absence of CAA

\subsubsection{APOE $\varepsilon 2$ and $C A A$}

Meta-analysis of the association of APOE $\varepsilon 2+$ versus $\varepsilon 2$ - genotypes with CAA among 11 studies (1640 participants) showed borderline significant decreased odds of CAA with APOE $\varepsilon 2+$ genotypes (OR $0.73,95 \%$ CI 0.53 to $1.00, \mathrm{p}=0.05$ ). Two studies (213 participants) provided a qualitative statement; neither reported a significant association. [60, 64] 


\subsubsection{Summary and discussion}

There is, therefore, robust evidence for a highly significant, dose-dependent association between APOE $\varepsilon 4$ and pathologically proven CAA, which does not vary significantly with dementia status, ethnicity, or study quality. However, there is no clear overall association between APOE $\varepsilon 2$ and histopathologically confirmed CAA. Lack of variation in the effect of APOE $\varepsilon 4$ by study size and the very large failsafe $N$ showed that this association could not plausibly be explained by publication, reporting or any other small study bias. It is important to note that the quality of studies included in our systematic review was generally limited when assessed against current reporting standards. [71,72] However, there were - reassuringly - no significant subgroup differences by study quality score.

The prevalence of CAA in Alzheimer's disease is over 70\% but the relationship between CAA and $\mathrm{AD}$ is still poorly understood. Although the diagnostic criteria for dementia and the participant inclusion criteria varied between the studies in our systematic review (some excluding cases with severe dementia), the demonstration of a similar association in those with and without clinical dementia suggests that the association of APOE $\varepsilon 4$ with CAA is independent of its known association with dementia (mainly Alzheimer's disease).

Pathological assessment in the included studies was very variable. Indeed, there is no widely accepted, standardized histopathological grading system for CAA, [74] and no comparative studies to determine the most accurate method for assessing CAA (although the suggested method is a combination of Thioflavin S/T or Congo Red with immunohistochemistry). [75] CAA assessment location also varied widely, possibly influencing the rate of CAA detection, since a greater burden of CAA is generally reported in the occipital or parietal lobes, albeit with a higher frequency of frontal lobe involvement reported in studies from China and Japan. [74] This is important because genetic associations may differ by CAA location and subtype. For example, there is preliminary evidence that APOE $\varepsilon 4$ may be associated with CAA type 1 (where CAA is found in cortical capillaries), and $\varepsilon 2$ with CAA type 2 (where amyloid is deposited in leptomeningeal and cortical vessels with the exception of cortical capillaries). [26] In addition, since APOE effects on ICH may vary with ethnicity, there may also be ethnic variation in genetic associations with CAA, but these have not yet been widely enough studied in non-white populations to assess this reliably. [76]

\subsection{Associations between other genetic polymorphisms and sporadic CAA}

In our systematic review, few polymorphisms other than APOE had been studied in more than a few hundred participants or in more than one study and there were not enough data for meta-analysis (Figure 1, Table 1). [39, 46, 50, 61, 63, 77-95] Thus, there were too few studies and participants to draw firm conclusions about the effect of other genetic polymorphisms. However, there were some suggestive positive associations with CAA. First, there was a consistent trend towards an association with CAA of a single nucleotoide polymorphism (SNP) in the transforming growth factor- $\beta 1$ (TGF- $\beta 1$ ) gene in two studies (449 participants). [82, 85] If real, this may occur through an influence of TGF- $\beta 1$ on $A \beta$ clearance and deposition through activation of astrocytes and microglia. Second, there were significant associations in one study (723 participants) of SNPs in the translocase of outer mitochondrial membrane 40 (TOMM40) 
gene with vascular amyloid burden but not with ICH attributed to CAA, [88] which could be through interaction of TOMM40 with APOE $\varepsilon 2$ or through its effects on A $\beta$ mitochondrial transport. Finally, one study (544 participants) found an association of a SNP in the complement component receptor 1 (CR1) gene with both CAA severity and ICH attributed to CAA, possibly occurring via altered clearance of $A \beta$ peptide. [96] Other studies found no overall significant associations, although some reported associations in particular subgroups (Table 1).

\begin{tabular}{|c|c|c|c|c|}
\hline Gene & Location / Polymorphism & $\begin{array}{l}\text { No. of } \\
\text { studies }\end{array}$ & $\begin{array}{c}\text { No. of } \\
\text { participants }\end{array}$ & Summary of results \\
\hline TGF- $\beta 1$ & rs1800470 & 2 & 449 & $\begin{array}{l}\text { Consistent trend for } \\
\text { positive association } \\
\text { between T allele and } \\
\text { CAA }\end{array}$ \\
\hline TOMM40 & $\begin{array}{c}\text { rs2075650, rs34404554, rs11556505, } \\
\text { rs769449, rs12972156, rs12972970, } \\
\text { rs157582, rs184017, rs157581, rs283815, } \\
\text { rs157580, rs439401, rs34095326, } \\
\text { rs10119 }\end{array}$ & 1 & 723 & $\begin{array}{l}\text { SNPs associated with } \\
\text { vascular amyloid burden }\end{array}$ \\
\hline CR1 gene & rs6656401 & 1 & 544 & $\begin{array}{l}\text { Associated with severity } \\
\text { of CAA pathology }\end{array}$ \\
\hline $\begin{array}{l}\text { LRP1 (low-density } \\
\text { lipoprotein receptor 1) }\end{array}$ & rs1799986 & 3 & 597 & \multirow{7}{*}{$\begin{array}{l}\text { No overall significant } \\
\text { associations } \\
\text { (inconsistent trends and } \\
\text { in some cases } \\
\text { associations in } \\
\text { subgroups) }\end{array}$} \\
\hline ACT (a1 antichymotrypsin) & $\begin{array}{c}\text { signal region of the gene } \rightarrow \mathrm{A} / \mathrm{T} \text { alleles } \\
\text { that determine the aminoacid alanine or } \\
\text { threonine }\end{array}$ & 2 & 235 & \\
\hline CYP46 & rs754203 & 2 & 524 & \\
\hline $\begin{array}{l}\text { ACE (angiotensin } 1 \\
\text { converting enzyme) }\end{array}$ & $\begin{array}{l}\text { intron } 16 \text { insertion/deletion of a } 287 \text { bp } \\
\text { sequence }\end{array}$ & 2 & 239 & \\
\hline Gene & & & & \\
\hline $\begin{array}{l}\text { PS1 (presenilin-1);BCHE (but } \\
\text { promoter;A2M (a2 macrogl } \\
\text { (neprilysin);OLR1 (oxidized I }\end{array}$ & $\begin{array}{l}\text { tyrylcholinesterase);DXS1047 locus;APOE } \\
\text { lobulin);PON1 (paraoxonase);NEP } \\
\text { low-density lipoprotein receptor 1);LRP }\end{array}$ & & & \\
\hline $\begin{array}{l}\text { (low density lipoprotein rec } \\
\mathrm{CH} 25 \mathrm{H}^{*} 1 \text {; VEGF (vascular en } \\
\text { factor);IL-1A;IL-1B;IL-33;GST } \\
\text { omega-1);SORL1 (sortilin rel } \\
\text { and AßPppromoter; }\end{array}$ & $\begin{array}{l}\text { eptor related protein);CYP46; } \\
\text { dothelial growth } \\
\text { TO1-1 (glutathione S-transferase } \\
\text { lated receptor);CTSD (cathepsin D); AßPP }\end{array}$ & 18 & $50-380^{*}$ & \\
\hline
\end{tabular}

*Range of participant numbers in individual studies ** probably rs4943

Adapted by permission from BMJ Publishing Group Limited, from "Genetics of cerebral amyloid angiopathy: systematic review and meta-analysis" Rannikmäe K, Samarasekera N, Martīnez-Gonzālez NA, Al-Shahi Salman R, Sudlow C. Journal of Neurology Neurosurgery and Psychiatry 2013;84(901-8)

Table 1. Summary of studies of non-APOE polymorphisms and CAA 


\section{APOE allele-specific associations with severe CAA-associated vasculopathy}

The systematic review and series of meta-analyses presented in the previous section confirmed an association between histopathologically diagnosed CAA and APOE $\varepsilon 4$, but not APOE $\varepsilon 2$. However a recent large scale genetic association study found that both $\varepsilon 2$ and $\varepsilon 4$ containing genotypes were associated with clinically diagnosed CAA, manifesting as lobar ICH attributed to CAA. [15] Furthermore, APOE $\varepsilon 2$ has been found to predict initial haematoma volume, haematoma expansion, increased mortality and poor functional outcome after lobar ICH. [17, 97] The currently favoured popular explanation for these findings is, that APOE $\varepsilon 4$ enhances deposition of amyloid- $\beta$ in cerebral blood vessel walls, while $\varepsilon 2$ promotes haemorrhage from amyloid-laden blood vessels by increasing specific CAA-related vasculopathic changes (Figure 5). [8, 25, 98]

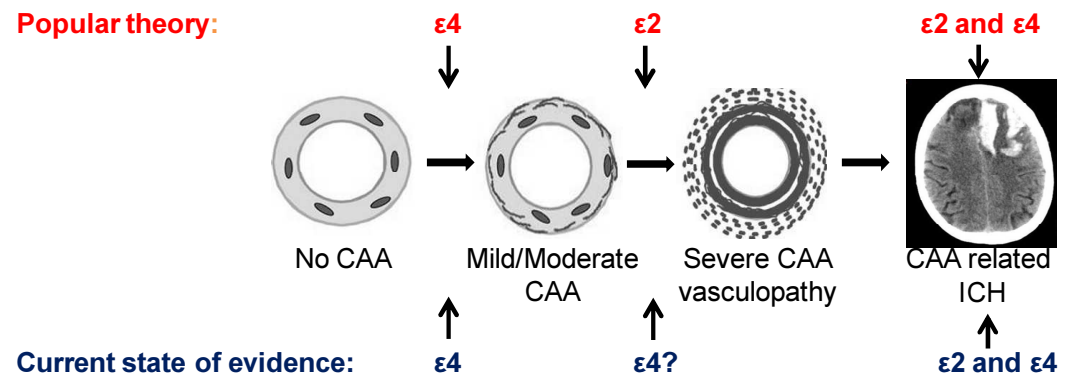

Adapted from Figure 1 in Acta Neuropathologica 2005;110: 345-359 "Sporadic cerebral amyloid angiopathy: pathology, clinical implications, and possible pathomechanisms", Johannes Attems, with kind permission from Springer Science and Business Media and Professor Attems.

Figure 5. Proposed theory and current state of evidence about associations between APOE and CAA phenotype

In a further recent systematic review, we reviewed the evidence for this hypothesis. [24] The main focus of this work was on assessing the potential influence of APOE genotypes on severe CAA preceding rupture. To avoid selection bias, we excluded studies with participants selected on the basis of having had a CAA-related ICH, since APOE $\varepsilon 2$ and $\varepsilon 4$ are already known to be associated with this phenotype, and severe CAA is commoner in such cases. This review sought all studies, which had conducted both APOE genotyping and histopathological assessment for CAA, including assessment for severe CAA with associated vasculopathic 
changes (blood vessel dilatation, microaneurysm formation, fibrinoid degeneration, cracking and double-barrelling of the vessel wall, and paravascular leakage of blood). The assessment for this severe form of CAA could have occurred either as part of the Vonsattel grading scale, [9] which includes such changes in its 'severe' category or through specifically reporting on some or all of the relevant histopathological characteristics. From 1754 publications screened, we identified six eligible studies, which included 543 eligible participants (Figure 1). [8, 25, 62, $64,99,100$ ] Only one of the six studies had previously reported on the association between the APOE genotype and severe CAA (assessed using Vonsattel scale), finding a significantly greater frequency of APOE $\varepsilon 2$ in severe versus moderate CAA cases. [25] This study and four others that had rated CAA on the Vonsattel scale, between them including 497 eligible participants (92\% of all 543 potentially eligible participants), $[62,64,99,100]$ were able to share their unpublished data for collaborative meta-analyses.

The five studies included in the meta-analyses used autopsy brains either from brain tissue banks or from a population-based prospective study with an autopsy component. There were 57 to 227 eligible participants per study, mean age at death was 78 to 84 years and about half of all participants were male. Three studies (357 participants) were conducted in predominantly white populations in the USA while information on ethnicity was unavailable for two studies (140 participants). About 50\% of participants had clinical dementia (mainly neuropathologically confirmed AD), about $20 \%$ were known not to be demented and in the remaining $30 \%$ dementia status was unknown. The quality of genotyping and of pathology assessment was generally very good when assessed against current reporting standards. [71, 72] As in the first of our two systematic reviews, methods for pathological assessment were variable, reflecting a lack of agreed standards for CAA pathology assessment at the time these studies were conducted. [24]

Among the 353 individuals in these five studies who had CAA present on histopathological assessment, meta-analyses found a significant association of $\varepsilon 4+$ versus $\varepsilon 4$ - genotypes with severe versus mild/moderate CAA (OR 2.5, 95\% CI 1.4 to $4.5, \mathrm{p}=0.002$ ) but no significant association with severe versus moderate CAA (OR 1.7, 95\% CI 0.9 to 3.1, p=0.11) (Figure 6). There was no significant heterogeneity between individual studies' results. For $\varepsilon 2+$ versus $\varepsilon 2-$ genotypes, the associations with severe CAA versus mild/moderate CAA and with severe versus moderate CAA were non-significant, with wide confidence intervals due to small numbers of participants, particularly in the $\varepsilon 2+$ group, which included 22 individuals, only seven of whom had severe CAA (Figure 7). There was moderate heterogeneity between individual studies' results for severe versus mild/moderate CAA $\left(\mathrm{I}^{2}=52 \% ; \chi_{3 \mathrm{~d} f}^{2}=6.2 ; \mathrm{p}=0.1\right)$ and minimal heterogeneity for severe versus moderate $\mathrm{CAA}\left(\mathrm{I}^{2}=11 \% ; \chi_{3 \mathrm{~d}}^{2}=3.4 ; \mathrm{p}=0.3\right)$. Results were similar and conclusions unchanged for the $\varepsilon 4+$ and $\varepsilon 2+$ genotypes when $\varepsilon 3 \varepsilon 3$ genotypes were used as the comparison group (rather than $\varepsilon 4$ - or $\varepsilon 2-$ ). Associations with the presence versus absence of CAA were consistent with results from the previous published systematic review [23], showing a clearly significant association with $\varepsilon 4+(\varepsilon 4+$ versus $\varepsilon 4-:$ OR $4.8,95 \%$ CI 3.0 to 7.6, $\mathrm{p}<0.00001)$ but not with $\varepsilon 2+$ genotypes ( $\varepsilon 2+$ versus $\varepsilon 2-:$ OR $0.38,95 \%$ CI 0.1 to $1.0, p=0.05)$. 


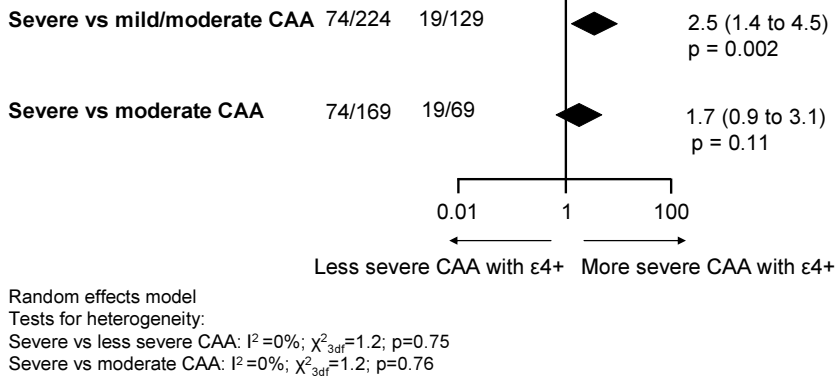

The diamonds represent pooled OR across studies and the width of the diamonds represents $95 \%$ confidence intervals (Cls).

${ }^{*} \varepsilon 4+$ : number of subjects with an $\varepsilon 4$ allele and severe CAA / total number of subjects with an $\varepsilon 4$ allele and any severity of CAA or severe/moderate CAA

$\varepsilon 4-:$ number of subjects without an $\varepsilon 4$ allele and severe CAA / total number of subjects without an $\varepsilon 4$ allele and any severity of CAA or severe/moderate CAA

Results of two studies conducted in one centre were combined for the analyses. $[25,64]$

Adapted by permission from BMJ Publishing Group Limited, from "APOE associations with severe CAA-associated vasculpathic changes: collaborative meta-analysis" Rannikmäe K, Kalaria RN, Greenberg SM, Chui HC, Schmitt FA, Samarasekera N, et al. Journal of Neurology Neurosurgery and Psychiatry 2014;85(3):300-5.

Figure 6. Meta-analysis of APOE-ع4 associations with severe CAA

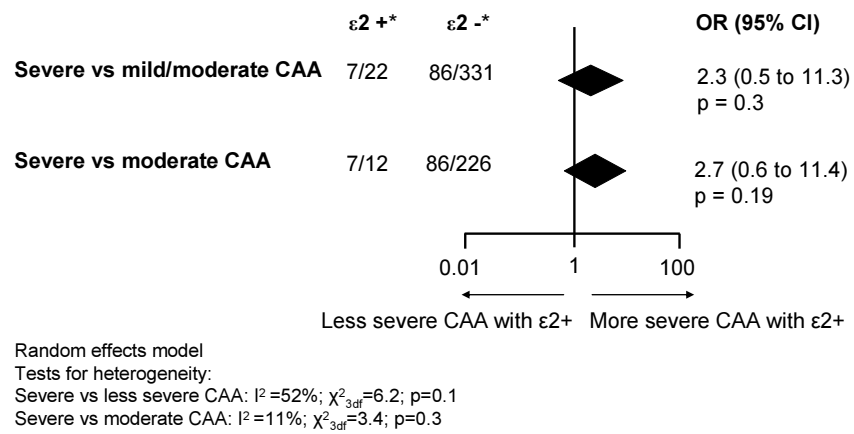

The diamonds represent pooled OR across studies and the width of the diamonds represents $95 \%$ confidence intervals (Cls). ${ }^{*} \varepsilon 2+$ : Number of subjects with an $\varepsilon 2$ allele and severe CAA / total number of subjects with an $\varepsilon 2$ allele and any severity of CAA or severe/moderate CAA $\varepsilon 2-:$ number of subjects without an $\varepsilon 2$ allele and severe CAA / total number of subjects without an $\varepsilon 2$ allele and any severity of CAA or severe/moderate CAA. Results of two studies conducted in one centre were combined for the analyses. $[25,64]$

Adapted by permission from BMJ Publishing Group Limited, from "APOE associations with severe CAA-associated vasculpathic changes: collaborative meta-analysis." Rannikmäe K, Kalaria RN, Greenberg SM, Chui HC, Schmitt FA, Samarasekera N, et al. Journal of Neurology Neurosurgery and Psychiatry 2014;85(3):300-5.

Figure 7. Meta-analysis of APOE $\varepsilon 2$ associations with severe CAA 
Thus, contrary to what has been suggested, $[8,25]$ a systematic assessment of the relevant evidence suggests a possible association of APOE $\varepsilon 4$ but not of APOE $\varepsilon 2$ with progression to severe CAA (Figure 5). However, this does not exclude a biologically meaningful association with $\mathrm{APOE} \varepsilon 2$ since, despite including data from almost all relevant cases from the published literature, total numbers of individuals included in our meta-analyses were relatively small and confidence intervals wide, especially for analyses of the effects of APOE $\varepsilon 2$. There were other limitations too. First, methods for histopathological assessment varied between studies, potentially introducing heterogeneity and reducing the likelihood of detecting a consistent effect across studies. Second, APOE allele-specific effects on severe CAA may differ according to the presence or absence of Alzheimer's disease, particularly for APOE $\varepsilon 2$, which has been associated with a decreased risk of Alzheimer's dementia. [101] Informative subgroup analysis to explore potential causes of heterogeneity could not be performed, however, because of the small overall numbers of participants and because dementia status was unknown for a large number of participants. Third, while the studies included assessed those severe CAAassociated vasculopathic changes that are specifically alluded to in the Vonsattel scale, other vasculopathic changes may also be relevant. Fourth, both APOE allele-specific and other genetic associations may differ by CAA subtype. The preliminary evidence that APOE $\varepsilon 4$ may be associated with CAA type 1 (where CAA is found in cortical capillaries), and $\varepsilon 2$ with CAA type 2 (where amyloid is deposited in leptomeningeal and cortical vessels with the exception of cortical capillaries) [26] suggests that CAA types 1 and 2 may represent different pathological entities, and - if so-the mechanisms and genetic risk factors for severe CAA and ICH could also differ. Finally, there may be other genetic influences that interact with APOE $\varepsilon 2$ to increase risk of or protect against severe CAA and $\mathrm{ICH}$.

\section{Conclusions}

There is strong evidence that APOE $\varepsilon 4$ promotes cerebral amyloid angiopathy, and further evidence to suggest that $\varepsilon 4$ may increase the risk of developing severe CAA among those with CAA. However, there is not convincing evidence to support the theory that APOE $\varepsilon 2$ promotes progression to severe CAA-related vasculopathic changes so leading to vessel rupture and ICH. Much larger numbers of individuals will need to be included in CAA histopathology studies if reliable conclusions are to be drawn about the specific effects of APOE $\varepsilon 2$, while bearing in mind that APOE genotype will not be the only genetic influence on CAA. Future research efforts in this area will also be helped substantially by the development and use of an internationally-agreed, standardised histopathological grading system for CAA (including assessment of CAA types 1 and 2), and by the consistent reporting of dementia - and specifically Alzheimer's disease - status [102] among individuals included in CAA histopathology studies. 


\section{Acknowledgements}

The authors would like to acknowledge for their scientific input Professor Rustam Al-Shahi Salman, Dr Neshika Samarasekera and Nahara Anani Martînez-Gonzâlez (Centre for Clinical Brain Sciences, University of Edinburgh, Edinburgh, UK), Professor Rajesh N Kalaria (Institute for Ageing and Health, Newcastle University, Newcastle upon Tyne, UK), Professor Steven M Greenberg (Department of Neurology, Stroke Research Centre, Massachusetts General Hospital, Boston, Massachusetts, USA), Professor Helena C Chui (Department of Neurology, University of Southern California, Los Angeles, California, USA) and Professor Frederick A Schmitt (Department of Neurology, Sanders-Brown Center on Aging, University of Kentucky, Lexington, Kentucky, USA).

\section{Author details}

Kristiina Rannikmäe ${ }^{1}$ and Cathie Sudlow ${ }^{1,2}$

*Address all correspondence to: cathie.sudlow@ed.ac.uk

1 Centre for Clinical Brain Sciences, University of Edinburgh, Edinburgh, UK

2 Institute for Genetics and Molecular Medicine, University of Edinburgh, Edinburgh, UK

\section{References}

[1] Revesz T, Holton JL, Lashley T, Plant G, Frangione B, Ristagno A et al. Genetics and molecular pathogenesis of sporadic and hereditary cerebral amyloid angiopathies. Acta Neuropathololgica 2009;118:115-30.

[2] Charidiomou A, Gang Q, Werring DJ. Sporadic cerebral amyloid angiopathy revisited: recent insights into pathophysiology and clinical spectrum. Journal of Neurology Neurosurgery and Psychiatry 2012;83(2)124-37.

[3] Samarasekera N, Smith C, Al-Shahi Salman R. The association between cerebral amyloid angiopathy and intracerebral haemorrhage: systematic review and meta-analysis. Journal of Neurology Neurosurgery and Psychiatry 2012;83(3)275-81.

[4] Chi NF, Chien LN, Ku HL, Hu CJ, Chiou HY. Alzheimer disease and risk of stroke: a population-based cohort study. Neurology 2013;80(8)705-11.

[5] Masuda J, Tanaka K, Ueda K, Omae T. Autopsy study of incidence and distribution of cerebral amyloid angiopathy in Hisayama, Japan. Stroke 1988;19(2)205-10.

[6] Neuropathology Group.Medical Research Council Cognitive Function and Aging Study. Pathological correlates of late-onset dementia in a multicentre, community 
based population in England and Wales. Neuropathology Group of the Medical Research Council Cognitive Function and Ageing Study (MRC CFAS). Lancet 2001;357(9251)169-75.

[7] Linn J, Halpin A, Demaerel P, Ruhland J, Giese AD, Dichgans M, et al. Prevalence of superficial siderosis in patients with cerebral amyloid angiopathy. Neurology 2010;74(17)1346-50.

[8] McCarron MO, Nicoll JA, Stewart J, Ironside JW, Mann DM, Love S, et al. The apolipoprotein E epsilon2 allele and the pathological features in cerebral amyloid angiopathy-related hemorrhage. Journal of Neuropathology and Experimental Neurology 1999;58(7)711-8.

[9] Vonsattel JPG, Myers RH, Hedley-Whyte ET, Ropper AH, Bird ED, Richardson EP Jr. Cerebral amyloid angiopathy without and with cerebral hemorrhages: a comparative histological study. Annals of Neurology 1991;30(5)637-49.

[10] Okazaki H, Reagan TJ, Campbell RJ. Clinicopathological studies of primary cerebral amyloid angiopathy. Mayo Clinic Proceedings 1979;54(1)22-31.

[11] Mandybur TI. Cerebral amyloid angiopathy: the vascular pathology and complications. Journal of Neuropathology and Experimental Neurology 1986;45(1)79-90.

[12] Eichner JE, Dunn ST, Perveen G, Thompson DM, Stewart KE, Stroehla BC. Apolipoprotein E polymorphism and cardiovascular disease: a HuGE review. American Journal of Epidemiology 2002;155(6)487-95.

[13] Paternoster L, Chen W, Sudlow CLM. Genetic determinants of white matter hyperintensities on brain scans: a systematic assessment of 19 candidate gene polymorphisms in 46 studies in 19, 000 subjects. Stroke 2009;40(6)2020-6.

[14] Sudlow C, Martḳnez Gonzilez NA, Kim J, Clark C. Does Apolipoprotein E genotype influence the risk of ischemic stroke, intracerebral hemorrhage, or subarachnoid hemorrhage? Systematic review and meta-analyses of 31 studies among 5961 cases and 17, 965 controls. Stroke 2006;37(2)364-70.

[15] Biffi A, Sonni A, Anderson CD, Kissela B, Jagiella JM, Schmidt H, et al. Variants of APOE influence risk of deep and lobar intracerebral hemorrhage. Annals of Neurology 2010;68(6)934-43.

[16] Maxwell SS, Jackson CA, Paternoster L, Cordonnier C, Thijs V, Al-Shahi Salman R, et al. Genetic associations with brain microbleeds: Systematic review and meta-analyses. Neurology 2011;77(2)158-67.

[17] Biffi A, Anderson CD, Jagiella JM, Schmidt H, Kissela B, Hansen BM, et al. APOE genotype and extent of bleeding and outcome in lobar intracerebral haemorrhage: a genetic association study. Lancet Neurology 2011;10(8)702-9. 
[18] Bertram L, McQueen MB, Mullin K, Blacker D, Tanzi RE. Systematic meta-analyses of Alzheimer disease genetic association studies: the AlzGene database. Nature Genetics 2007;39(1)17-23.

[19] Lambert MP, Barlow AK, Chromy BA, Edwards C, Freed R, Liosatos M, et al. Diffusible, nonfibrillar ligands derived from Abeta1-42 are potent central nervous system neurotoxins. Proceedings of the National Academy of Sciences of the United States of America 1998;95(11)6448-53.

[20] Wood SJ, Chan W, Wetzel R. Seeding of A beta fibril formation is inhibited by all three isotypes of apolipoprotein E. Biochemistry 1996;35(38)12623-8.

[21] Holtzman DM, Bales KR, Wu S, Bhat P, Parsadanian M, Fagan AM, et al. Expression of human apolipoprotein $\mathrm{E}$ reduces amyloid-beta deposition in a mouse model of Alzheimer's disease. The Journal of Clinical Investigation 1999;103(6)R15-R21.

[22] Holtzman DM, Bales KR, Tenkova T, Fagan AM, Parsadanian M, Sartorius LJ, et al. Apolipoprotein $\mathrm{E}$ isoform-dependent amyloid deposition and neuritic degeneration in a mouse model of Alzheimer's disease. Proceedings of the National Academy of Sciences of the United States of America 2000;97(6)2892-7.

[23] Rannikmäe K, Samarasekera N, Martīnez-Gonzālez NA, Al-Shahi Salman R, Sudlow C. Genetics of cerebral amyloid angiopathy: systematic review and meta-analysis. Journal of Neurology Neurosurgery and Psychiatry 2013;84(8)901-8.

[24] Rannikmäe K, Kalaria RN, Greenberg SM, Chui HC, Schmitt FA, Samarasekera N, et al. APOE associations with severe CAA-associated vasculpathic changes: collaborative meta-analysis. Journal of Neurology Neurosurgery and Psychiatry 2014;85(3): 300-5.

[25] Greenberg SM, Vonsattel JP, Segal AZ, Chiu RI, Clatworthy AE, Liao A, et al. Association of apolipoprotein E epsilon2 and vasculopathy in cerebral amyloid angiopathy. Neurology 1998;50(4)961-5.

[26] Thal DR, Ghebremedhin E, Rüb U, Yamaguchi H, Del Tredici K, Braak H. Two types of sporadic cerebral amyloid angiopathy. Journal of Neuropathology and Experimental Neurology 2002;61(3)282-93.

[27] Thomas AJ, Morris CM, Ferrier IN, Kalaria RN. Distribution of amyloid beta 42 in relation to the cerebral microvasculature in an elderly cohort with Alzheimer's disease. Annals of the New York Academy of Sciences 2000;903(83-8.

[28] Alafuzoff I, Aho L, Helisalmi S, Mannermaa A, Soininen H. Beta-amyloid deposition in brains of subjects with diabetes. Neuropathology and applied neurobiology 2009;35(1)60-8.

[29] Attems J, Lauda F, Jellinger KA. Unexpectedly low prevalence of intracerebral hemorrhages in sporadic cerebral amyloid angiopathy: An autopsy study. Journal of Neurology 2008;255(1)70-6. 
[30] Berg L, McKeel DW Jr, Miller JP, Storandt M, Rubin EH, Morris JC, et al. Clinicopathologic studies in cognitively healthy aging and Alzheimer disease: Relation of histologic markers to dementia severity, age, sex, and apolipoprotein E genotype. Archives of Neurology 1998;55(3)326-35.

[31] Etiene D, Kraft J, Ganju N, Gomez-Isla T, Gemelli B, Hyman BT, et al. Cerebrovascular pathology contributes to the heterogeneity of Alzheimer's disease. Journal of Alzheimer's Disease 1998;1(2)119-34.

[32] Honig LS, Kukull W, Mayeux R. Atherosclerosis and AD: analysis of data from the US National Alzheimer's Coordinating Center. Neurology 2005;64(3)494-500.

[33] Jicha GA, Parisi JE, Dickson DW, Cha RH, Johnson KA, Smith GE, et al. Age and apoE associations with complex pathologic features in Alzheimer's disease. Journal of the Neurological Sciences 2008;273(1-2)34-9.

[34] Lashley T, Holton JL, Gray E, Kirkham K, O'Sullivan SS, Hilbig A, et al. Cortical alpha-synuclein load is associated with amyloid-beta plaque burden in a subset of Parkinson's disease patients. Acta neuropathologica 2008;115(4)417-25.

[35] Lewis H, Beher D, Cookson N, Oakley A, Piggott M, Morris CM, et al. Quantification of Alzheimer pathology in ageing and dementia: age-related accumulation of amyloid-beta(42) peptide in vascular dementia. Neuropathology and applied neurobiology 2006;32(2)103-18.

[36] Love S, Nicoll JA, Hughes A, Wilcock GK. APOE and cerebral amyloid angiopathy in the elderly. NeuroReport 2003;14(11)1535-6.

[37] Oyama F, Shimada H, Oyama R, Ihara Y. Apolipoprotein E genotype, Alzheimer's pathologies and related gene expression in the aged population. Molecular Brain Research 1995;29(1)92-8.

[38] Petrovitch H, Ross GW, He Q, Uyehara-Lock J, Markesbery W, Davis D, et al. Characterization of Japanese-American men with a single neocortical AD lesion type. Neurobiology of aging 2008;29(10)1448-55.

[39] Peuralinna T, Tanskanen M, Mäkela M, Polvikoski T, Paetau A, Kalimo H, et al. $\mathrm{APOE}$ and AbeetaPP gene variation in cortical and cerebrovascular amyloid-beeta pathology and Alzheimer's Disease: a population-based analysis. Journal of Alzheimer's Disease 2011;26(2)377-85.

[40] Roher AE, Kuo YM, Esh C, Knebel C, Weiss N, Kalback W, et al. Cortical and leptomeningeal cerebrovascular amyloid and white matter pathology in Alzheimer's disease. Molecular Medicine 2003;9(3-4)112-22.

[41] Sonnen JA, Larson EB, Walker RL, Haneuse S, Crane PK, Gray SL, et al. Nonsteroidal anti-inflammatory drugs are associated with increased neuritic plaques. Neurology 2010;75(13)1203-10. 
[42] Stopa EG, Butala P, Salloway S, Johanson CE, Gonzalez L, Tavares R, et al. Cerebral cortical arteriolar angiopathy, vascular beta-amyloid, smooth muscle actin, Braak stage, and APOE genotype. Stroke 2008;39(3)814-21.

[43] Tiraboschi P, Sabbagh MN, Hansen LA, Salmon DP, Merdes A, Gamst A, et al. Alzheimer disease without neocortical neurofibrillary tangles: "A second look". Neurology 2004;62(7)1141-7.

[44] Caselli RJ, Walker D, Sue L, Sabbagh M, Beach T. Amyloid load in nondemented brains correlates with APOE e4. Neuroscience Letters 2010;473(3)168-71.

[45] Cruz-Sinchez FF, Durany N, Thome J, Riederer P, Zambón D. Correlation between apolipoprotein-E polymorphism and Alzheimer's disease pathology. Journal of Alzheimer's Disease 2000;2(3-4)223-9.

[46] Durany N, Ravid R, Riederer P, Cruz-Sinchez FF. Increased frequency of the alpha-1antichymotrypsin $\mathrm{T}$ allele in cerebral amyloid angiopathy. Neuropathology 2000;20(3)184-9.

[47] Nelson PT, Abner EL, Schmitt FA, Kryscio RJ, Jicha GA, Smith CD, et al. Modeling the association between 43 different clinical and pathological variables and the severity of cognitive impairment in a large autopsy cohort of elderly persons. Brain Pathology 2010;20(1)66-79.

[48] Nicoll JA, Savva GM, Stewart J, Matthews FE, Brayne C, Ince P, et al. Association between APOE genotype, neuropathology and dementia in the older population of England and Wales. Neuropathology and applied neurobiology 2011;37(3)285-94.

[49] Olichney JM, Hansen LA, Hofstetter CR, Lee JH, Katzman R, Thal LJ. Association between severe cerebral amyloid angiopathy and cerebrovascular lesions in Alzheimer disease is not a spurious one attributable to apolipoprotein E4. Archives of Neurology 2000;57(6)869-74.

[50] Pahnke J, Walker LC, Schroeder E, Vogelgesang S, Stausske D, Walther R, et al. Cerebral beeta-amyloid deposition is augmented by the -491AA promoter polymorphism in non-demented elderly individuals bearing the apolipoprotein E e4 allele. Acta neuropathologica 2003;105(1)25-9.

[51] Pfeifer LA, White LR, Ross GW, Petrovitch H, Launer LJ. Cerebral amyloid angiopathy and cognitive function: The HAAS autopsy study. Neurology 2002;58(11)1629-34.

[52] Premkumar DR, Cohen DL, Hedera P, Friedland RP, Kalaria RN. Apolipoprotein Eepsilon4 alleles in cerebral amyloid angiopathy and cerebrovascular pathology associated with Alzheimer's disease. The American Journal of Pathology 1996;148(6)2083-95. 
[53] Schneider JA, Bienias JL, Wilson RS, Berry-Kravis E, Evans DA, Bennett DA. The apolipoprotein E epsilon4 allele increases the odds of chronic cerebral infarction detected at autopsy in older persons. Stroke 2005;36(5)954-9.

[54] Walker LC, Pahnke J, Madauss M, Vogelgesang S, Pahnke A, Herbst EW, et al. Apolipoprotein E4 promotes the early deposition of Abeta42 and then Abeta40 in the elderly. Acta neuropathologica 2000;100(1)36-42.

[55] Yamada M. Risk factors for cerebral amyloid angiopathy in the elderly. Annals of the New York Academy of Sciences 2002;977(37-44.

[56] Yamaguchi H, Sugihara S, Ogawa A, Oshima N, Ihara Y. Alzheimer beta amyloid deposition enhanced by ApoE 4 gene precedes neurofibrillary pathology in the frontal association cortex of nondemented senior subjects. Journal of Neuropathology and Experimental Neurology 2001;60(7)731-9.

[57] Zipser BD, Johanson CE, Gonzalez L, Berzin TM, Tavares R, Hulette CM, et al. Microvascular injury and blood-brain barrier leakage in Alzheimer's disease. Neurobiology of aging 2007;28(7)977-86.

[58] Alafuzoff I, Seppo H, Mannermaa A, Riekkinen P Sr, Soininen H. Beta-amyloid load is not influenced by the severity of cardiovascular disease in aged and demented patients. Stroke 1999;30(3)613-8.

[59] Attems J, Jellinger KA, Lintner F. Alzheimer's disease pathology influences severity and topographical distribution of cerebral amyloid angiopathy. Acta neuropathologica $2005 ; 110(3) 222-31$.

[60] Chalmers K, Wilcock GK, Love S. APOE epsilon 4 influences the pathological phenotype of Alzheimer's disease by favouring cerebrovascular over parenchymal accumulation of A beta protein. Neuropathology and applied neurobiology 2003;29(3)231-8.

[61] Christoforidis M, Schober R, Krohn K. Genetic-morphologic association study: Association between the low density lipoprotein-receptor related protein (LRP) and cerebral amyloid angiopathy. Neuropathology and applied neurobiology 2005;31(1)11-9.

[62] Chui HC, Zarow C, Mack WJ, Ellis WG, Zheng L, Jagust WJ, et al. Cognitive impact of subcortical vascular and Alzheimer's disease pathology. Annals of Neurology 2006;60(6)677-87.

[63] Davidson Y, Gibbons L, Pritchard A, Hardicre J, Wren J, Tian J, et al. Genetic associations between cathepsin D exon $2 \mathrm{C}->\mathrm{T}$ polymorphism and Alzheimer's disease, and pathological correlations with genotype. Journal of Neurology, Neurosurgery and Psychiatry 2006;77(4)515-7.

[64] Greenberg SM, Rebeck GW, Vonsattel JP, Gomez-Isla T, Hyman BT. Apolipoprotein E epsilon 4 and cerebral hemorrhage associated with amyloid angiopathy. Annals of Neurology 1995;38(2)254-9. 
[65] Leclercq PD, Murray LS, Smith C, Graham DI, Nicoll JAR, Gentleman SM. Cerebral amyloid angiopathy in traumatic brain injury: Association with apolipoprotein $\mathrm{E}$ genotype. Journal of Neurology, Neurosurgery and Psychiatry 2005;76(2)229-33.

[66] Mortimer JA, Snowdon DA, Markesbery WR. The effect of APOE-e4 on dementia is mediated by Alzheimer neuropathology. Alzheimer Disease and Associated Disorders 2009;23(2)152-7.

[67] Tanskanen M, Lindsberg PJ, Tienari PJ, Polvikoski T, Sulkava R, Verkkoniemi A, et al. Cerebral amyloid angiopathy in a 95+cohort: Complement activation and apolipoprotein E (ApoE) genotype. Neuropathology and applied neurobiology 2005;31(6)589-99.

[68] Yip AG, Mckee AC, Green RC, Wells J, Young H, Cupples LA, et al. APOE, vascular pathology, and the AD brain. Neurology 2005;65(2)259-65.

[69] Zarow C, Zaias B, Lyness SA, Chui H. Cerebral amyloid angiopathy in Alzheimer disease is associated with apolipoprotein E4 and cortical neuron loss. Alzheimer Disease and Associated Disorders 1999;13(1)1-8.

[70] Zubenko GS, Stiffler S, Stabler S, Kopp U, Hughes HB, Cohen BM, et al. Association of the apolipoprotein E epsilon 4 allele with clinical subtypes of autopsy-confirmed Alzheimer's disease. American Journal of Medical Genetics 1994;54(3)199-205.

[71] Stroup DF, Berlin JA, Morton SC, Olkin I, Williamson GD, Rennie D, et al. Meta-analysis of observational studies in epidemiology: a proposal for reporting. Meta-analysis of Observational Studies in Epidemiology (MOOSE) group. JAMA: the journal of the American Medical Association 2000;283(15)2008-12.

[72] Little J, Higgins JPT, Ioannidis JPA, Moher D, Gagnon F, von Elm E, et al. STrenghtening the REporting of Genetic Association Studies (STREGA) - An Extension of the STROBE Statement. PLoS medicine 2009;6(2)e22.

[73] Rosenthal R. The file drawer problem and tolerance for null results. Psychological Bulletin 1979;86(3)638-41.

[74] Chen YW, Lee MJ, Smith EE. Cerebral amyloid angiopathy in East and West. International Journal of Stroke 2010;5(5)403-11.

[75] Attems J. Sporadic cerebral amyloid angiopathy: Pathology, clinical implications, and possible pathomechanisms. Acta neuropathologica 2005;110(4)345-59.

[76] Tzourio C, Arima H, Harrap S, Anderson C, Godin O, Woodward M, et al. APOE genotype, ethnicity, and the risk of cerebral hemorrhage. Neurology 2008;70(16)1322-8.

[77] Biffi A, Shulman JM, Jagiella JM, Cortellini L, Ayres AM, Schwab K, et al. Genetic variation at CR1 increases risk of cerebral amyloid angiopathy. Neurology 2012;78(5)334-41. 
[78] Chalmers KA, Culpan D, Kehoe PG, Wilcock GK, Hughes A, Love S. APOE promoter, ACE1 and CYP46 polymorphisms and beta-amyloid in Alzheimer's disease. NeuroReport 2004;15(1)95-8.

[79] Chapuis J, Tian J, Shi J, Bensemain F, Cottel D, Lendon C, et al. Association study of the vascular endothelial growth factor gene with the risk of developing Alzheimer's disease. Neurobiology of aging 2006;27(9)1212-5.

[80] Chapuis J, Hot D, Hansmannel F, Kerdraon O, Ferreira S, Hubans C, et al. Transcriptomic and genetic studies identify IL-33 as a candidate gene for Alzheimer's disease. Molecular Psychiatry 2009;14(11)1004-16.

[81] Cuenco KT, Lunetta KL, Baldwin CT, Mckee AC, Guo J, Cupples LA, et al. Association of distinct variants in SORL1 with cerebrovascular and neurodegenerative changes related to Alzheimer disease. Archives of Neurology 2008;65(12)1640-8.

[82] Hamaguchi T, Okino S, Sodeyama N, Itoh Y, Takahashi A, Otomo E, et al. Association of a polymorphism of the transforming growth factor-beta1 gene with cerebral amyloid angiopathy. Journal of Neurology, Neurosurgery and Psychiatry 2005;76(5)696-9.

[83] Kölsch H, Larionov S, Dedeck O, Orantes M, Birkenmeier G, Griffin WST, et al. Association of the glutathione S-transferase omega-1 Ala140Asp polymorphism with cerebrovascular atherosclerosis and plaque-associated interleukin-1alpha expression. Stroke 2007;38(10)2847-50.

[84] Lendon CL, Thaker U, Harris JM, McDonagh AM, Lambert JC, Chartier-Harlin MC, et al. The angiotensin 1-converting enzyme insertion (I)/deletion (D) polymorphism does not influence the extent of amyloid or tau pathology in patients with sporadic Alzheimer's disease. Neuroscience Letters 2002;328(3)314-8.

[85] Peila R, Yucesoy B, White LR, Johnson V, Kashon ML, Wu K, et al. A TGF-beta1 polymorphism association with dementia and neuropathologies: the HAAS. Neurobiology of aging 2007;28(9)1367-73.

[86] Shi J, Tian J, Pritchard A, Lendon C, Lambert JC, Iwatsubo T, et al. A 3'-UTR polymorphism in the oxidized LDL receptor 1 gene increases Abeta40 load as cerebral amyloid angiopathy in Alzheimer's disease. Acta neuropathologica 2006;111(1)15-20.

[87] Thal DR, Papassotiropoulos A, Saido TC, Griffin WS, Mrak RE, Kölsch H, et al. Capillary cerebral amyloid angiopathy identifies a distinct APOE epsilon4-associated subtype of sporadic Alzheimer's disease. Acta neuropathologica 2010;120(2)169-83.

[88] Valant V, Keenan BT, Anderson CD, Shulman JM, Devan WJ, Ayres AM, et al. TOMM40 in cerebral amyloid angiopathy related intracerebral hemorrhage: comparative genetic analysis with Alzheimer's disease. Translational Stroke Research 2012;3(S1)S102-S112. 
[89] Yamada M, Sodeyama N, Itoh Y, Suematsu N, Otomo E, Matsushita M, et al. Association of presenilin-1 polymorphism with cerebral amyloid angiopathy in the elderly. Stroke 1997;28(11)2219-21.

[90] Yamada M, Sodeyama N, Itoh Y, Suematsu N, Otomo E, Matsushita M, et al. Butyrylcholinesterase K variant and cerebral amyloid angiopathy. Stroke 1998;29(12)2488-90.

[91] Yamada M, Sodeyama N, Itoh Y, Suematsu N, Otomo E, Matsushita M, et al. Association of alpha1 antichymotrypsin polymorphism with cerebral amyloid angiopathy. Annals of Neurology 1998;44(1)129-31.

[92] Yamada M, Sodeyama N, Itoh Y, Suematsu N, Otomo E, Matsushita M, et al. A deletion polymorphism of alpha2 macroglobulin gene and cerebral amyloid angiopathy. Stroke 1999;30(11)2277-9.

[93] Yamada M, Sodeyama N, Itoh Y, Otomo E, Matsushita M, Mizusawa H. No association of paraoxonase genotype or atherosclerosis with cerebral amyloid angiopathy. Stroke 2002;33(4)896-900.

[94] Yamada M, Sodeyama N, Itoh Y, Takahashi A, Otomo E, Matsushita M, et al. Association of neprilysin polymorphism with cerebral amyloid angiopathy. Journal of Neurology Neurosurgery and Psychiatry 2003;74(6)749-51.

[95] Zubenko GS, Hughes HB, Stiffler JS. Clinical and neurobiological correlates of DXS1047 genotype in Alzheimer's disease. Biological Psychiatry 1999;46(2)173-81.

[96] Chibnik LB, Shulman JM, Leurgans SE, Schneider JA, Wilson RS, Tran D, et al. CR1 is associated with amyloid plaque burden and age-related cognitive decline. Annals of Neurology 2011;69(3)560-9.

[97] Brouwers HB, Biffi A, Ayres AM, Schwab K, Cortellini L, Romero JM, et al. Apolipoprotein $\mathrm{E}$ genotype predicts hematoma expansion in lobar intracerebral hemorrhage. Stroke 2012;43(6)1490-5.

[98] McCarron MO, Nicoll JAR. Apolipoprotein E genotype and cerebral amyloid angiopathy related hemorrhage. Annals of the New York Academy of Sciences 2000;903(176-9.

[99] Kalaria RN, Premkumar DRD. Apolipoprotein E genotype and cerebral amyloid angiopathy. Lancet 1995;346(8987)1424.

[100] Davis DG, Schmitt FA, Wekstein DR, Markesbery WR. Alzheimer neuropathologic alterations in aged cognitively normal subjects. Journal of Neuropathology and Experimental Neurology 1999;58(4)376-88.

[101] Verghese PB, Castellano JM, Holtzman DM. Apolipoprotein E in Alzheimer's disease and other neurological disorders. Lancet Neurology 2011;10(3)241-52. 
[102] Dubois B, Feldman HH, Jacova C, Cummings JL, Dekosky ST, Barberger-Gateau P, et al. Revising the definition of Alzheimer's disease: a new lexicon. Lancet Neurology 2013;9(11)1118-27. 